\title{
COLONIALIDADE E POLÍTICA DO ESQUECIMENTO ${ }^{1}$
}

\author{
Wagner Vinhas ${ }^{2}$ \\ Doutor em Estudos étnicos e Africanos (UFBA) \\ Professor do Instituto Federal da Bahia \\ wagnervinhas@ifba.edu.br
}

\begin{abstract}
Resumo: O artigo busca refletir o silenciamento da intelectualidade negra brasileira. Reportome às estratégias para silenciar homens e mulheres negros cuja prática social consiste naquilo que denominamos por política do esquecimento e cujo mecanismo consiste em se apagar da memória das novas gerações a contribuição de autores negros e negras. É nesse sentido que o dilema da intelectualidade negra no Brasil reside na herança racista do campo intelectual brasileiro - um duplo vínculo - ordem científica e ordem social. Em discordância do que diz a teoria bourdiana, presume-se que o acúmulo de capital específico não pode justificar a ausência de autores negros e negras no campo intelectual brasileiro. Tudo leva a crer que, no Brasil, o que determina a posição no campo intelectual vai além da incorporação de um tipo de capital específico - classe, escolaridade, origem - transferido para o campo intelectual de um espaço social circundante: raça, gênero, classe.
\end{abstract}

Palavras-Chaves: Colonialidade; Política do esquecimento; Intelectualidade negra; Dilema; Corpus teórico.

\section{COLONIALITY AND POLITICS OF FORGETFULNESS}

Abstract: The article aims at reflecting on the silencing of the Brazilian black intelligentsia. I refer to the strategies to silence black men and women whose social practice consists of what we call the politics of forgetfulness and whose mechanism is to erase from the memory of the new generations the contribution of black authors. It is in this sense that the dilemma of black intellectuality in Brazil lies in the racist heritage of the Brazilian intellectual field - a double bond - scientific and social order. In disagreement with what the Bourdean theory says, it is assumed that the accumulation of specific capital cannot justify the absence of black authors in the Brazilian intellectual field. Everything suggests that, in Brazil, what determines the position in the intellectual field goes beyond the incorporation of a specific type of capital - class, education, origin - transferred to the intellectual field of a surrounding social space: race, gender, class.

Keywords: Coloniality; Politics of forgetfulness; Black intellectuality; Dilemma; Theoretical corpus.

\footnotetext{
1 Texto recebido em: 10/08/2019; Texto aprovado em: 20/12/2019.

${ }^{2}$ Currículo Lattes: http://lattes.cnpq.br/2282661157795995.
} 


\section{INTRODUÇÃO}

Este artigo busca refletir acerca do silenciamento da intelectualidade negra brasileira. Reporto-me às estratégias para silenciar homens e mulheres negros, reconhecidos e que se reconhecem como intelectuais da população negra no Brasil. Ângela Figueiredo e Ranon Grosfuguel (2007) chamam essa prática social de política do esquecimento cujo mecanismo consiste em se apagar da memória das novas gerações a contribuição de autores negros e negras. Portanto, a ausência da intelectualidade negra no campo intelectual brasileiro não pode ser explicada pelo acúmulo de um capital específico, mas pela predominância da ordem social sobre a ordem científica na qual coloca em suspenso um tipo de capital acumulado a favor das hierarquias forjadas na dinâmica social brasileira. ${ }^{3}$ De acordo com Ângela Figueiredo e Osmundo Pinho (2002), a estrutura do campo seria uma ordem consumada, determinada pelo vínculo entre ordem científica e ordem social, uma vez que o campo não se descola das estruturas sociais circundantes, mas transfere e retira poder desse vínculo. Para Bourdieu (2011) diferentes tipos de capital correspondem aos distintos critérios de diferenciação na construção do espaço social. Pierre Bourdieu (1983b) ainda afirma que é possível inferir que o campo intelectual consiste em um sistema de forças, ou melhor, os agentes podem ser descritos como forças que, ao surgirem, se opõem e se agregam, configurando uma estrutura específica em um dado momento no tempo.

Então, a proposta, aqui, é refletir um dilema da intelectualidade negra que consiste em fazer parte de uma pratica social de conhecimento vinculada ao modo de vida da população negra e, por isso, fora dos critérios estabelecidos por um microcosmo social que incorpora elementos determinantes de uma sociedade com rígidas hierarquias da ordem social: raça, gênero, classe. Por outro lado, um exame mais cuidadoso da questão revela que o pretendido apagamento é relativo quando tomamos por intelectualidade uma definição mais abrangente e, portanto, forjada em espaços acadêmicos e não acadêmicos. Isso pode ser verificado examinando a memória coletiva vinculada aos movimentos sociais e políticos em estreita relação com a doutrinação de militantes e a formação de intelectuais negros e negras no Brasil.

\footnotetext{
${ }^{3}$ Para Bourdieu (2011) diferentes tipos de capital correspondem aos distintos critérios de diferenciação na construção do espaço social.
} 


\section{Política do Esquecimento:}

Para os que acreditam que homens e mulheres negros são silenciados pelo campo intelectual brasileiro, o argumento se desenvolve da seguinte maneira: na historiografia desse microcosmo social, encontramos nomes da intelectualidade negra que, apesar da relativa visibilidade em sua época, beiram o apagamento completo da memória nacional. As estratégias por detrás desse silenciamento se dariam por diferentes maneiras de tentar desqualificar o trabalho científico e a capacidade intelectiva de autores negros e negras: excessivo interesse pela temática negra acarretando a falta de distanciamento epistemológico; o engajamento na militância negra comprometendo os critérios de objetividade da investigação; o despreparo dos intelectuais negros e negras quando comparados à competência dos brancos; o possível isolamento especialmente dos que estão politicamente comprometidos no combate da desigualdade racial e do racismo. Isso causaria os dilemas vividos por homens e mulheres negros nas disputas ocorridas no campo intelectual brasileiro. Nesse trabalho, acrescento outra dimensão a esse argumento: um dos dilemas de intelectuais negros e negras está na herança racista do campo intelectual brasileiro. Como argumenta Sandra Azerêdo (1994), raça se constitui em relações de poder que beneficia e oprime os que delas participam. Desse modo, as regras desse campo específico incorporam elementos determinantes de uma organização social que refrata as hierarquias rígidas da herança racista - e sexista - da sociedade nacional.

$\mathrm{Na}$ historiografia do campo intelectual brasileiro, encontramos nomes da intelectualidade negra que, apesar da relativa visibilidade em sua época, beiram o apagamento completo da memória nacional. Como exemplo, é possível citar Luiz Gama [1830 - 1882], Monteiro Lopes [1867-1910], Hemetério dos Santos [1858 - 1939], Lino Guedes [1897 - 1951], Solano Trindade [1908 - 1974], Edison Carneiro [1912 - 1972], Abdias do Nascimento [1914 2011], Guerreiro Ramos [1915 - 1982], Clóvis Moura [1925 - 2003], Eduardo de Oliveira e Oliveira [1924 - 1980], Lélia Gonzalez [1935 - 1994] e Beatriz Nascimento [1942 - 1995] . Partindo de Ângela Figueiredo e Ramón Grosfoguel (2007) pode-se argumentar que são casos

\footnotetext{
${ }^{4}$ Alex Ratts (2006) argumenta que, dez anos depois da morte de Beatriz Nascimento, ela foi referenciada pela intelectualidade negra vinculada aos movimentos negros, mas não havia sido citada em trabalhos acadêmicos. No entanto, encontrei em Lélia Gonzalez (1982) e em Abdias do Nascimento (1980) referências ao trabalho de Beatriz Nascimento.
} 
relacionados à política do esquecimento cujo mecanismo responde pelo apagamento da contribuição de autores negros e negras das novas gerações.

Ao tomar como referência Raymond Aron (1980), é possível dizer que existem várias definições de intelectualidade e muitas maneiras de conceituar o quadro de pensadores de uma época. Então, a pergunta inicial poderia ser: a quem se destinaria o exercício da atividade intelectual? Antonio Gramsci (1982), filósofo italiano, acredita que a distinção entre intelectual e não intelectual se refere tão somente à função social da categoria profissional dos intelectuais. Para Antonio Gramsci (1982), é possível argumentar que não existe um trabalho puramente físico, apartado de um mínimo de qualificação técnica, ou seja, sem um exercício intelectual criador. O chamado intelectual orgânico seria formado por uma classe com a intenção de tornálo o seu especialista e organizador. É dessa forma que a intelectualidade negra vem sendo forjada historicamente em disputas no campo intelectual - mesmo levando em conta a extrema desvantagem dos outsiders. ${ }^{5}$ Partindo de Gramsci, Spivak (2010) formula uma acepção para o intelectual subalterno na qual condiz com as camadas baixas da sociedade e forjadas pelas exclusões dos mercados, das representações políticas e legal, bem como pela impossibilidade de se tornarem membros plenos no estrato social dominante. Por sua vez, questiona a ideia de discurso de resistência que parte dos que julgam poder falar pelo outro, e por meio dele, reproduzindo as estruturas de poder e opressão ao manter o chamado subalterno silenciado. Milton Santos (2000) defendia uma prática intelectual capaz de fornecer um contra discurso a um sistema autoritário instaurado em diversas instâncias da sociedade. Para Edward Said (2005), o intelectual seria um destruidor de estereótipos e de categorias reducionistas que limitam a comunicação e o pensamento humano. Segundo Cornel West (1993/1994), a escolha por se tornar um intelectual negro é um ato de marginalidade auto imposta, na qual garante um status periférico dentro e para a comunidade negra. De acordo com Florentina Souza (2010), a função de intelectual implica em propor representações de si e de suas culturas e discuti-las em espaços que extrapolam a fronteira do privado. Gayatri Chakravorty Spivak (2010) acredita que a tarefa do intelectual seria criar espaços para que o sujeito subalterno possa falar e possa ser ouvido.

\footnotetext{
${ }^{5}$ Em uma tradução literal, outsiders significa os de fora, forasteiros. É um conceito proposto por Norbert Elias e John Scotson (2000) para abordar situações em que numa comunidade, grupo ou sociedade, existem os estabelecidos - coesos e integrados - por isso mesmo, superiores e poderosos; e os de fora, não inseridos no grupo - desconsiderados e marginalizados.
} 
Por intelectualidade negra, entendo um grupo social reconhecido, que também se reconhece como intelectual negro e negra, cuja atuação em espaços públicos - academias, organizações, movimentos, partidos políticos - reafirma a posição de advogar pelas causas da população negra. Acrescento que a intelectualidade negra na qual me refiro também parte de um reconhecimento da sua própria cumplicidade no processo de silenciamento do outro, mas que torna esse reconhecimento um espaço produtivo na medida em que questiona o lugar de onde teoriza. Por isso, a intelectualidade negra também é um convite para pensar o intelectual ativista, como sugere Alex Ratts (2006) ou, ainda, indo além dos limites da formação acadêmica, aceitar a impossibilidade de reivindicar um distanciamento epistemológico entre o teórico e o ativista, como propõe Homi Bhabha (1998).

Tais negociações entre política e teoria tornam impossível pensar o lugar do teórico como uma meta narrativa que pede uma forma mais total de generalidade. Tampouco é possível reivindicar uma certa distância epistemológica familiar entre o tempo $e$ lugar do intelectual e do ativista, como sugere Fanon quando observa que "enquanto os políticos situam sua ação em acontecimentos do momento, os homens de cultura se posicionam no campo da história" (p. 58).

Há também de se considerar que, na historiografia da intelectualidade negra, existem trajetórias que não estão relacionadas a espaços acadêmicos, mas, nem por isso, deixam de ser reconhecidas como produtoras de um conhecimento científico. ${ }^{6}$ Nilma Gomes (2010) argumenta que a produção da intelectualidade negra seria uma atividade realizada com auxílio de organizações coletivas - próximo do que Bruno Latour (2005) chama por Teoria do AtorRede $^{7}$ ou Jean-François Sirinelli (1998), de estrutura de sociabilidade ${ }^{8}$ - cujo objetivo seria dar maior visibilidade aos grupos sócio-raciais silenciados. A noção de rede a que me refiro também estaria próxima da ideia de quilombismo proposta por Abdias do Nascimento (1980), ou seja, algo que envolve associações, irmandades, confrarias, clubes, grêmios, terreiros, escolas de samba:

Com efeito, o quilombismo tem se revelado fator capaz de mobilizar disciplinarmente as massas negras por causa do profundo apelo psicossocial cujas raízes estão entranhadas na história, na cultura e na vivência dos afro-brasileiros. [...] O modelo

\footnotetext{
${ }^{6}$ Refiro-me a mães e pais de santo, mestres de capoeira, homens e mulheres de ofício e a pessoas que fizeram parte da militância negra no século XX. Há também temas científicos debatidos fora dos muros da academia em que os sujeitos envolvidos são considerados: questão de gênero discutida sobretudo por mulheres, e de raça, por negros. ${ }^{7}$ A teoria do Ator-Rede consiste em pensar o mundo social por meio de um princípio de simetria generalizada que exige uma explicação simultânea sobre a natureza e a sociedade, os humanos e os não-humanos.

${ }^{8}$ Seriam as redes às quais os intelectuais aderem, como revistas, conselhos editoriais, partidos políticos. (SIRINELLI, 1998)
} 
quilombista vem atuando como ideia-força, energia que inspira modelos de organização dinâmica desde o século XV. Nessa dinâmica quase sempre heroica, o quilombismo está em constante reatualização, atendendo exigências do tempo histórico e situações do meio geográfico (p. 338-339).

Florentina Souza (2013) afirma que o negro brasileiro é exaltado enquanto objeto de pesquisa, mas normalmente excluído da atividade de pesquisador por essa prática ser considerada prerrogativa de brancos. No racismo à brasileira, lembra Souza, a intelectualidade do país sempre esteve atenta ao lugar étnico-racial desse grupo social, seja para exaltá-lo como pessoa de alma branca, seja para depreciá-lo em áreas exclusivamente destinadas aos brancos. bell hHooks (1995) defende que, além dos preconceitos raciais presentes na sociedade, a intelectual negra também enfrentaria as discriminações de cunho sexista da estrutura patriarcal. ${ }^{9}$ O trabalho intelectual não seria considerado uma atividade para mulheres e isso levaria muitas delas a desistirem de estudar ou a não encontrarem motivação para continuar o percurso acadêmico (HOOKS, 1995, RATTS, 2005), ou ainda a ter de enfrentar o que Sandra Azerêdo (1994) chama de tradição acadêmica patrilinear. De acordo com Spivak (2010) a mulher subalterna encontra-se em uma posição ainda mais periférica na medida em que enfrenta os problemas de gênero que a coloca no mais profundo obscurantismo.

Suponho que a animosidade do campo intelectual brasileiro com a intelectualidade negra ocorra pelo incômodo em relação à reinterpretação da história da nação protagonizada pelo grupo subalterno, ou porque os temas trabalhados por intelectuais negros e negras sejam considerados "ideologizados", como explica João Baptista Borges, citado por Alex Ratts (2006). O embaraço da história revisitada pode ser constatado com a denúncia feita por esse grupo de intelectuais relativamente à omissão do microcosmo social no que se refere à violência sexual cometida contra a mulher africana e afro-brasileira. Essa postura omissa teria se apoiado no discurso harmonioso da teoria luso-tropicalista que serve de fundamento para o chamado mito da democracia racial brasileira (NASCIMENTO, 1976a; NASCIMENTO, 1980; GONZALEZ, 1982). Em outro momento, a intelectualidade negra chamou atenção também para a ligação oculta entre o apadrinhamento brasileiro e o tipo de relação de poder contido na noção de cordialidade brasileira (NASCIMENTO, 1976a; NASCIMENTO, 1982). A recusa à produção da intelectualidade negra seria outra forma de negar a legitimidade das práticas sociais

\footnotetext{
${ }^{9}$ Vale ressaltar o que Alex Ratts (2006), citando Vagner Gonçalvez, afirma sobre o esquecimento de intelectuais negros como Manuel Querino, Edison Carneiro, Zora Neale Hurtson e a intelectual estadunidense Ruth Landes, cujos trabalhos foram alvo de preconceitos racistas e sexistas no campo intelectual.
} 
de conhecimento - vinculadas ao modo de vida da população negra - cujo trabalho de sistematização pode ser considerado um empreendimento intelectual. Portanto, em parte, o silenciamento de autores negros e negras deve ser atribuído a sua posicionalidade dentro do campo intelectual brasileiro: raça, gênero, classe.

Há muitas maneiras de tentar desqualificar o trabalho científico e a capacidade intelectiva da intelectualidade negra. Uma delas seria considerar o interesse por uma temática que diz respeito a ela mesma e que, por isso, resultaria em falta de distanciamento epistemológico. Outra alegação seria o engajamento na militância negra, uma vez que a perspectiva política vai de encontro aos critérios de objetividade requeridos para a investigação do conjunto de fenômenos sociais. Há também o argumento infundado do despreparo dos intelectuais negros e negras quando comparados à competência dos brancos. O possível isolamento, em especial dos que estão politicamente comprometidos com o combate da desigualdade racial e do racismo, também seria considerado um motivo para a ausência da intelectualidade negra no campo intelectual brasileiro.

\begin{abstract}
O campo de estudos conhecidos como "estudos das relações raciais" no Brasil constituem o objeto de conhecimento historicamente produzido por acadêmicos brancos cuja epistemologia baseia-se no estudo sobre negros, por isso mesmo, a noção de estudos sobre as "relações raciais" mantém o mito de uma horizontalidade entre os grupos racialmente diferenciados (FIGUEIREDO E GROSFOGUEL, 2007, p. 36).
\end{abstract}

Ângela Figueiredo e Ramón Grosfoguel (2009) afirmam que a dificuldade de reconhecer o racismo institucional comprometeria a associação de práticas cotidianas de desqualificação como possíveis causas do desestímulo na trajetória acadêmica dos negros. Seja como for, as consequências desse processo são inquestionáveis: 1) ausência de uma bibliografia de autores negros e negras em cursos acadêmicos; 2) desconhecimento da contribuição da intelectualidade negra; 3) desinteresse pelos conteúdos produzidos e pelo contexto políticointelectual em que eles foram elaborados. Por sua vez, o grau de desconhecimento dos trabalhos da intelectualidade negra pode ser verificado pelo pouco número de citações, traduções e premiações entre os pare $^{10}$, bem como pela pouca leitura da produção intelectual negra em cursos de graduação e pós-graduação, para retomar à proposta mertoniana (COLE e COLE, 1967).

\footnotetext{
${ }^{10}$ Alex Ratts (2006), citando Vagner Gonçalves Silva, também considera a citação uma forma de visibilidade acadêmica.
} 
Consciente ou inconscientemente, raramente os autores negros estão nas bibliografias dos cursos ministrados nas universidades. Consequentemente, poucas vezes temos tido a oportunidade de conhecer a contribuição desses autores, refletindo, inclusive, não apenas sobre o conteúdo de seus trabalhos, mas sobre o contexto políticointelectual em que foram produzidos (FIGUEIREDO E GROSFOGUEL, 2007, p. 36).

Figueiredo e Grosfoguel (2007) argumentam que a ausência de debates da produção intelectual de autores e autoras negros ocorre devido a geopolítica do conhecimento que minimiza a produção da intelectualidade negra em favor de uma cultura acadêmica específica e em conformidade com um tipo de capital social e simbólico. Retomando uma crítica de Spivak (2010) o subalterno é muitas vezes impedido de falar, e quando tenta falar não é ouvido. Isso ocorre porque o ato de representar - falar por ou re-presentar - não se concretiza para o sujeito subalterno uma vez que se encontra desvinculado de qualquer forma de agenciamento que assegure a transação entre o falante e o ouvinte, ou seja, haveria ausência do caráter dialógico na fala do subalterno. Resumidamente, pode-se argumentar que a fala desse outro é sempre intermediada pela voz de outrem - autorizado, legitimado -, que reivindica para si algo em nome do sujeito subalterno.

A crítica ao discurso epistemológico ocidental se baseia, inicialmente, na ideia de que somente pelo conhecimento das práticas sociais é possível assegurar as condições de produção e validação do conhecimento. A inflexão da reflexão epistemológica desloca a soberania epistêmica para o social. Isso leva à contra argumentação de que não é possível determinar os critérios de avaliação e validação que não estejam ancorados em contextos históricos específicos. O conhecimento seria produto das relações sociais - experiência intencional e inteligível, e produção intelectual por meio de práticas e de atores sociais - e, por isso, daria origem a diferentes epistemologias.

\footnotetext{
No sentido mais amplo, as relações sociais são sempre culturais (intra-culturais ou inter-culturais) e políticas (representam distribuições desiguais de poder). Assim sendo, qualquer conhecimento válido é sempre contextual, tanto em termos de diferença cultural como em termos de diferença política. Para além de certos patamares de diferença cultural e política, as experiências são constituídas por vários conhecimentos, cada um com os seus critérios de validade, ou seja, são constituídos por conhecimentos rivais. (SANTOS, 2010, p. 09).
}

Figueiredo e Grosfoguel (2007) também afirmam que as redes compostas por pesquisadores brancos excluem os poucos membros da intelectualidade negra. Spivak (2010), por sua vez, defende que uma das mais notáveis formas de violência epistêmica diz respeito ao 
projeto orquestrado de constituir o sujeito subalterno como Outro. Dessa forma, fica evidente que o racismo no Brasil não se manifesta somente como discriminação, mas também como dominação e subjugação do trabalho, da subjetividade, da autoridade, bem como da sexualidade, da cultura e da identidade. São aspectos que formam um padrão de poder - que alguns autores chamam de colonialidade - o qual articula diversas dimensões da existência social (MENESES, 2005; FIGUEIREDO e GROSFOGUEL, 2007; QUIJANO, 2010; SANTOS, 2012). Quando Aníbal Quijano (2010) propôs a noção de colonialidade do saber, queria demonstrar como as relações de poder contemporâneas implicam a persistência da colonização epistêmica, bem como a manutenção dos estereótipos e das formas de discriminação e dominação.

\begin{abstract}
A colonialidade permite-nos compreender a continuidade das formas coloniais de dominação após o fim das administrações coloniais, produzidas pelas culturas coloniais e pelas estruturas do sistema-mundo capitalista moderno/colonial. A expressão "colonialidade do poder" designa um processo fundamental de estruturação do sistema-mundo moderno/colonial, que articula os lugares periféricos da divisão internacional do trabalho com a hierarquia étnico-racial global e com a inscrição de migrantes do Terceiro Mundo na hierarquia étnico-racial das cidades metropolitanas globais (GROSFOGUEL, 2008, p. 55).
\end{abstract}

A colonialidade implica múltiplas relações de poder imbricadas: sexuais, políticas, epistêmicas, econômicas, espirituais, linguísticas, raciais. Cada uma delas se constitui num padrão hierárquico que tem como base o racismo e que pode variar segundo os critérios de discriminação vigente em cada lugar (SANTOS, 2012). Grosfoguel (2008) defende que ninguém está livre das hierarquias de classe, sexo, gênero, religião, língua e raça do sistemamundo patriarcal/capitalista/colonial/moderno. A noção de raça se referiria tão somente a uma experiência de dominação colonial cuja consequência nos dias atuais está relacionada com a dominação de uma racionalidade específica, ou seja, o eurocentrismo.

\footnotetext{
O eurocentrismo não é exclusivamente, portanto, a perspectiva cognitiva dos europeus, ou apenas os dominantes do capitalismo mundial, mas um conjunto de educados sob a sua hegemonia. E embora isso implique um componente etnocêntrico, este não o explica, nem é a sua fonte principal de sentido. Trata-se da perspectiva cognitiva durante o longo tempo do conjunto do mundo eurocentrado do capitalismo colonial/moderno e que naturaliza a experiência dos indivíduos neste padrão de poder. Ou seja, fá-las entender como naturais, consequentemente como dadas, não susceptíveis de ser questionadas (QUIJANO, 2010, p.75).
}

Os europeus não só teriam sido eficazes no controle das formas de trabalho, como também na definição da configuração intersubjetiva, incorporando histórias culturais e 
intelectuais. A colonialidade resultaria na repressão das demais práticas sociais de conhecimento e de produção de sentido, inclusive as do universo simbólico e as do padrão de expressão e de objetivação da subjetividade. Nesse sentido, a colonialidade do saber seria a evidência do legado epistemológico eurocêntrico que impede grupos e povos subalternizados de compreenderem o mundo a partir do mundo em que vivem e das epistemes que lhe são próprias (QUIJANO, 2010).

Para finalizar, uma das mais contundentes críticas à estrutura da epistemologia europeia surge com a retomada do conceito "pós-colonial" e com a releitura do processo de colonização e das grandes narrativas - ou metanarrativas - centrada no ideário de nação. Stuart Hall (2003) defende que o valor teórico da noção "pós-colonial” consiste na crítica à ideia de binarismo presente nas estratégias dos intelectuais conservadores e dos intelectuais de esquerda.

Consequentemente, o termo "pós-colonial" não se restringe a descrever uma determinada sociedade ou época. Ele relê a "colonização" como parte de um processo global especificamente transnacional e transcultural, e produz uma reescrita descentrada, diaspórica ou "global" das grandes narrativas imperiais do passado, centradas na nação. (HALL, 2003, p. 109).

A contribuição do conceito estaria na possibilidade de dar notoriedade às novas histórias, às temporalidades, às diferenças, às especificidades - ou às contextualidades - para também compor as narrativas de nação. Nesse sentido, a intelectualidade negra brasileira tem participado da crítica à geopolítica do conhecimento. Ela responde pela análise pautada na denúncia da perspectiva eurocêntrica dos cânones brasileiros e no uso de critérios hierárquicos - étnico-raciais - de validação do conhecimento. Além disso, compartilhariam, entre outros princípios, a necessidade de revisar a historiografia do negro e, consequentemente, de retificar aquilo que foi dito ou escrito sobre a contribuição negra na sociedade brasileira. É na perspectiva de uma literatura revisionária (VINHAS, 2010) que abordo, no próximo tópico, o conjunto de práticas discursivas chamado "estudo das relações étnico-raciais".

\section{CORPUS TEÓRICO: BEATRIZ, LÉLIA E ABDIAS}

O que chamo de intelectualidade negra refere-se tanto a um grupo social organicamente criado e ciente da sua função social, quanto a uma unidade discursiva. ${ }^{11}$ Parto

\footnotetext{
${ }^{11}$ Para Roberto Machado (1981), a unidade discursiva foucaultiana é uma dispersão de elementos. Os discursos seriam uma dispersão, ou seja, não estão ligados por nenhum princípio de unidade que não seja pura dispersão de
} 
dessa assertiva para propor que intelectualidade negra também se refere ao projeto de descrição de acontecimentos de discurso cuja evidencia revela o domínio de enunciados ${ }^{12}$ efetivamente falados ou escritos (FOUCAULT, 1987). ${ }^{13} \mathrm{O}$ tratamento de tal conjunto possibilita evidenciar as intenções dos sujeitos falantes e a construção dos objetos de discurso. Em outras palavras, sua posicionalidade de sujeito enunciador. A análise da formação discursiva ajuda a refletir a existência das regularidades - objetos, modalidades enunciativas, conceitos e estratégias - e acompanhar a dispersão de elementos numa unidade discursiva. A intenção, aqui, não é tanto falar da intelectualidade negra como um grupo social, mas, como um corpus em que se compartilha a mesma visão das coisas, delineia-se o mesmo campo perceptivo e uma análise comum. A existência da unidade discursiva pressupõe esse corpus que chamamos de estudos das relações étnico-raciais ${ }^{14}$ cujo trabalho consiste em consolidar um paradigma no sentido kuhniano. ${ }^{15}$

Gilles Deleuze (1987) tem razão ao afirmar que a definição foucaultiana de corpus estabelece uma relação com palavras, frases e proposições, considerando a simples função que exerce em seu conjunto. Somente o exame desse conjunto seria capaz de demonstrar onde os objetos podem surgir e como recebem as qualificações de quilombo, racismo, negritude e mulher negra. É dessa forma que a intelectualidade negra - enquanto acontecimento discursivo - não pode ser caracterizada apenas pelos objetos que lhe são atribuídos - mulher negra, negritude, racismo, quilombo -, mas também, acima de tudo, pela maneira como esses objetos

elementos do discurso. Portanto, a análise do discurso em Foucault remete à descrição de uma dispersão que estabelece as regularidades e que funciona como lei de dispersão ou sistemas de dispersão entre elementos do discurso que operam como uma forma de regularidade.

${ }^{12}$ Por enunciado, Foucault (1987) entende qualquer série de signos, de figuras, grafismos ou traços.

${ }^{13}$ Conforme Roberto Machado (1981), o discurso em Foucault não obedece às distribuições tradicionais: ciência, poesia, romance. Portanto, seria ele capaz de dar conta de todos os domínios sem estar limitado a qualquer uma destas divisões.

${ }^{14}$ Partindo das definições do Dictionary of Race and Ethnic Relations, é possível argumentar que a expressão se refere a casos particulares de relação social. Essa particularidade tem sido vista como a relação entre grupos que utilizam a ideia de etnia e de raça para estruturar sua ação e reação uns para com os outros. Entre as décadas de 1950 e 1960, os pesquisadores estadunidenses concordavam que as relações sociais dessa natureza eram uma categoria real e distinta das demais relações sociais. Concluem, assim, que etnia e raça são fenômenos socialmente construídos, havendo relação entre os grupos resultantes dessa construção social. A outra abordagem conclui que as relações étnico-raciais são uma forma específica de relacionamento, envolvendo pessoas que acreditam na existência étnica e racial, e, por isso, organizam suas relações com os demais com base nessa crença. O estudo das relações étnico-raciais procuraria analisar as relações entre conjuntos de fatores entre os quais estaria o racismo. A presença da discriminação é presumida desde o início. A análise, então, toma a forma de uma pesquisa por suas origens, remontando, de modo etiológico, à elaboração do pensamento racista, à consideração dos seus efeitos comportamentais e cognitivos e à importância funcional para a cultura (CASHMORE, 1994).

${ }^{15}$ Para Kuhn (2003), o paradigma determina os problemas, os fatos e o objeto de reconstrução interpretativa, ou seja, o modelo ou padrão aceito. 
foram formados. A condição de emergência dos objetos estaria vinculada às circunstâncias do seu aparecimento histórico e, portanto, às diferentes coisas que foram ditas sobre eles: semelhanças e diferenças; aproximações e distanciamentos. Nesse sentido, não poderia ser estudada isoladamente, mas levando em consideração o conjunto de instituições, processos sociais e políticos, bem como as formas de comportamento. ${ }^{16} \mathrm{O}$ que caracteriza um corpus não é tanto o tema, mas a perspectiva como ele é trabalhado. No século XIX, os estudos das relações étnico-raciais se voltam para a subjugação de povos não europeus através de um modelo evolutivo cujas populações eram classificadas em escalas de superioridade e inferioridade. No final do século XX, em particular a partir da década de 1960, o estudo das relações étnicoraciais se empenha numa perspectiva engajada de denúncia do racismo e de revisão historiográfica dos povos submetidos à colonização moderna.

Procuro demonstrar que a produção intelectual de Beatriz Nascimento pode ser situada no que Foucault (1987) denomina de unidade discursiva. Portanto, caberia esclarecer as regularidades e as dispersões, bem como as regras que possibilitam a sua existência. Assim, a intenção seria situá-la em um feixe de relações - unidade discursiva/corpus - e demonstrar como os níveis - objetos, modalidades enunciativas, conceitos e estratégias - ajudam a entender o que chamo de intelectualidade negra. Para realizar tal tarefa, trago para o debate dois nomes contemporâneos de Beatriz Nascimento, a saber, Lélia Gonzalez e Abdias do Nascimento. A escolha parte da possibilidade de demonstrar que, além de compartilharem um conjunto de enunciações, também participaram de encontros e debates em torno do que é denominado de “estudos das relações étnico-raciais" no Brasil. ${ }^{17}$ Mas, acima de tudo, por conta das suas posicionalidades - raça, gênero, classe - frente às questões tratadas enquanto sujeitos de fala. O que proponho não é uma exaustiva demonstração dessa produção intelectual, mas evidenciar como, no decurso dessa produção, estiveram envolvidos com temas, lugares e percepções. ${ }^{18}$

\footnotetext{
${ }^{16}$ Inicialmente, a formação das modalidades discursivas estaria envolvida com quem fala e com os critérios de competência e saber para proferir semelhante discurso. Em seguida, seria preciso demonstrar onde o discurso foi obtido, nesse caso, o discurso intelectual não só do tipo acadêmico, como também ativista, poético, performático, pedagógico. Finalmente, seria necessário identificar a posição que o sujeito falante ocupa em uma rede de informações: de origem acadêmica ou militante; proveniente de encontros, congressos, seminários; advinda do papel exercido como palestrante ou ouvinte (FOUCAULT, 1987).

${ }^{17}$ A tríade intelectual esteve junta em encontros como a $10^{\mathrm{a}}$ Semana de Estudos sobre a Contribuição do Negro na Formação Social Brasileira e na Conscientização da Cultura Afro-brasileira, em 1984; no Seminário Brasil e Dakar Pan-African Conference, em 1987; no $1^{\circ}$ Fórum Estadual sobre o Ensino da História das Civilizações Africanas na Escola Pública, em 1991. Ver Apêndice B.

${ }^{18}$ Basta lembrar que Beatriz Nascimento foi professora no Estado do Rio de Janeiro, membro-fundadora do GTAR. Lélia Gonzalez foi professora da PUC/RJ, fez parte do Movimento Negro Unificado e do Movimento de Mulheres,
} 
A problemática central do pensamento de Beatriz Nascimento foi o fenômeno do quilombo. De fato, trata-se de uma experiência histórica presente em inúmeros debates realizados no Brasil, mais intensamente discutida após a década de $1960 .{ }^{19}$ A tríade intelectual compartilhava a ideia de que em todo o continente americano haveria existido focos de resistência africana ${ }^{20}$ e indícios de sistemas sociais alternativos que corresponderiam à organização de quilombos no Brasil: cimarrones, cumbes, palenques, morronages e marronsocieties.

Para Beatriz Nascimento (1982c):

Deste modo o Kilombo se transfere para a América. Através destes indivíduos, em todo o território americano foram fundados a partir do século XVI os estabelecimentos quilombos (Brasil e Cone Sul), Cimarróns (ao norte da América do Sul), Apalancados (em Cuba e Haiti) e Marrons (nas demais ilhas do Caribe) (p. 26).

Lélia Gonzalez (1988a) argumentava que:

E foi no interior das novas sociedades que se formaram no Novo Mundo (sejam de segregação aberta ou disfarçada), que a amefricanidade floresceu e se estruturou. Já na época colonial-escravista, ela se manifestava nas revoltas, na elaboração de estratégias de resistência cultural, no desenvolvimento de formas alternativas de organização social livre, cuja expressão concreta está nos quilombos, cimarrones, cumbes, palenques, morronages e marron societies, que surgiram nas mais distintas paragens geográficas da América (p. 24).

Abdias do Nascimento (1982a) dizia que:

Trouxemos conosco, desde a África, a força do nosso espírito, das nossas instituições socioeconômicas e políticas, de nossa religião, arte e cultural. É essa a essência do nosso conceito de quilombo. [...] Celebremos a tradição africana de luta, expressa nos milhares de quilombos militantes espalhados através do território e da história brasileiras. Celebramos Jabaguara (São Paulo), Campo Grande (Minas Gerais), Tutiaçu (Maranhão) e todos os demais quilombos irmãos disseminados pela terra e pelo tempo brasileiros. Estas comunidades percorriam o espectro que abrangia desde a minúscula vila isolada às populações de milhares (p. 26).

bem como foi candidata à deputada federal pelo PT, elegendo-se primeira suplente, em 1982. Em 1986, candidatou-se à deputada estadual pelo PDT, novamente elegendo-se suplente. Abdias do Nascimento foi professor da Universidade do Estado de Nova York, deputado federal pelo PDT de 1983 a 1987 e senador da República de 1997 a 1999, assumindo a vaga após a morte de Darcy Ribeiro.

${ }^{19}$ Para João José Reis e Flávio dos Santos Gomes (1996), a popularização dos estudos sobre o quilombo data da década de 1930, seguindo os passos deixados por Nina Rodrigues, Arthur Ramos, Edison Carneiro e, mais tarde, Roger Bastide. Desde as décadas de 1920 e 1930, há indícios da influência desta temática no Centro Cívico Palmares, de onde mais tarde sairia alguns dos fundadores da Frente Negra Brasileira. Há também intelectuais, como Aderbal Jurema, escrevendo, nessa época, sobre o quilombo como um episódio de luta de classes no Brasil. Os trabalhos de Edison Gomes e Clóvis Moura também sinalizavam para a emergência da temática na perspectiva marxista. Há, no final da década de 1950, uma tentativa de questionar a visão harmoniosa de Gilberto Freyre, através das análises da chamada Escola Paulista, da qual faziam parte Florestan Fernandes, Fernando Henrique Cardoso, Octávio Ianni e, mais tarde, com Luís Luna, José Alípio Goulart e Décio Freitas.

${ }^{20}$ Para Reis e Gomes (1996), onde houve escravidão houve resistência. 
Beatriz Nascimento (1985) discordava de uma definição de quilombo capaz de englobar toda e qualquer forma de sistemas alternativos. Para a autora, não se poderia comparar uma organização com milhares de negros - do tipo Estado ou República ${ }^{21}$ - aos núcleos negros com poucos indivíduos. Portanto, uma definição globalizante de quilombo recairia no mesmo erro quando

\begin{abstract}
Simbolicamente como quase tudo que se refere à História do negro no Brasil o conceito de quilombo como "valhacouto de negros" permaneceu na historiografia, na literatura, e no glossário idiomático (dicionário) como um lugar de bandidos ou de idílicos, que sonhavam com uma possível volta ao estado "tradicional" africano. Estado também considerado República negra. O que não é de todo falso. Essa visão apoia-se no episódio em que Ganga Zumba permite e aceita trégua com o Império Ultramarino português. Estas relações foram de nível de Estado para Estado. Esta forma de quilombo tem seu exemplo unicamente em Palmares. Entretanto os historiadores de quilombo, de um modo geral amplia esta característica, generalizando para os demais (NASCIMENTO, 1985, p. 01-02).
\end{abstract}

O que chamo de intelectualidade negra não se limita a compartilhar um ponto de vista ou um mesmo objeto ou um conceito comum. O que faz dela uma unidade discursiva é participar de um sistema de relações ou ser tomada por uma visão comum ou ser considerada um feixe de relações. Nesse sentido, a tríade concordaria que as diferentes formas de enunciar a história do negro implicam confluir a vontade de conhecer o passado com o desejo de revelar o que ficou oculto da história oficial.

Eu quero dizer o seguinte: o preto, diante da História do Brasil, se sente eternamente escravo, o eternamente vencido, incapaz de reagir diante da situação que foi colocada no Brasil. Mas isso é uma deformação total que a historiografia procura trazer e que já não corresponde mais à situação de classe baixa que o negro brasileiro geralmente está, de falta de instrução, de falta de condições econômicas, mas que está basicamente estruturado dentro de um arcabouço ideológico de grandes implicações. [...] Então, o quilombo pra gente, pro negro, tem uma importância fundamental porque enquanto escravidão, o negro como escravo, ele historicamente termina de existir no final do século passado, 1888 , se projeta todo tipo de vida no negro e que não aquela da fazenda, mas que já existia e preexistia à abolição (NASCIMENTO, 1977, p. 03-04).

\footnotetext{
${ }^{21}$ Para Clóvis Moura (2001), elevar o quilombo ao status de Estado provocaria uma situação em que os senhores estabeleceriam uma relação com os aquilombados diferente da que teriam com seus escravos. Isso porque precisaria firmar uma linguagem que não fosse entre o senhor e o escravo, mas tendo que considerar o quilombola como aquele que está fora do controle e da disciplina despótica, na medida em que a relação é mediada por categorias de oposição radical.
} 
Lélia Gonzalez (1982) cita Beatriz Nascimento (1974a, 1979, 1981, 1985) para argumentar de que maneira o estudo do fenômeno do quilombo lançaria luz sobre uma história renovada do Brasil e dos negros:

Assim como a história do povo brasileiro foi outra, o mesmo acontece com o povo negro especialmente. Ele sempre buscou formas de resistência contra a situação subhumana em que foi lançado. De acordo com as informações que obtivemos da historiadora negra Maria Beatriz Nascimento, já em 1559 se tem notícia da formação dos primeiros quilombos, essas formas alternativas de sociedade, na região das plantações de cana do nordeste (p.90).

O tom denunciador de Abdias do Nascimento (1980) não esconde o desejo pela revisão da historiografia de uma nação que falseia a concepção de história ao excluir propositadamente o negro:

\begin{abstract}
A história do Brasil é uma versão concebida por brancos, para os brancos e pelos brancos, exatamente como toda sua estrutura econômica, sócio-cultural, política e militar tem sido usurpada da maioria da população para o benefício exclusivo de uma elite minoritária brancóide, presumidamente de origem europeia. [...] A falsa imagem de uma escravidão humanizada, benemérita, com certa "liberdade", tem sido atribuída ao Brasil como também à região de modo geral (p. 28-29).
\end{abstract}

Há certos conceitos que denotam a correlação de enunciados em que os esquemas retóricos fazem parte do mesmo grupo enunciativo - o racismo como uma neurose da cultura brasileira: o negro por adoção (Beatriz Nascimento, 1974b) ${ }^{22}$; o racismo por denegação (Lélia Gonzalez, 1988a), e a autonegação (Abdias do Nascimento, 1982a):

Ser negro por adoção é uma tarefa tão simples quanto falsa. Nela se esconde a tentativa de permanecer o quadro racial dominante, é uma forma sofisticada de apresentar sob forma de paternalismo o preconceito de quem não pode negar uma origem que repudia; de quem deve maior parte do que possui ao povo que escravizou e desumanizou (NASCIMENTO, 1974b, p. 66).

Lélia Gonzalez (1988a) dizia que:

Enquanto denegação dessa ladinoamefricanidade, o racismo se volta justamente contra aqueles que, do ponto de vista étnico, são os testemunhos vivos da mesma, tentando tirá-los de cena, apagá-los do mapa (p. 23).

Abdias do Nascimento (1982a) afirmava que:

A integração significava a renúncia da especificidade cultural e política da comunidade negra, cuja identidade própria seria absorvida pela sociedade dominante à qual se integraria. Seria esse um conceito alheiro à experiência brasileira, o qual só

\footnotetext{
${ }^{22}$ Alex Ratts (2006) conclui que esta categoria seria forjada na ambivalência entre o branco que deseja representar o pai e aquele que almeja alcançar o lugar do irmão. Em ambos os casos, não evitariam o posicionamento e a visão etnocêntrica do pesquisador branco.
} 
poderia ser colhido no exterior? Pelo contrário. Através de minha experiência de luta afro-brasileira, desde a década de 1930 até 1968, quando saí do país, já havia chegado a essa conclusão. Pois a chamada "integração" racial brasileira significava, e significa, na prática, apenas a subordinação e a dependência do negro ao paternalismo do banco, que detém todos os recursos e os concede, apenas, ao negro que se mantém subalterno, humilde e conciliador. [...] Dessa forma, a experiência prática de tentar travar uma luta a favor da identidade específica do negro e da sua valorização dentro da sociedade brasileira já havia me levado, muito antes de chegar aos Estados Unidos, à conclusão de que a chamada integração racial não seria nunca a solução do racismo no Brasil: a integração do negro aos padrões exógenos da cultura dominante eurocêntrica significa a sua autonegação (p. 19).

A tríade de pensadores responde por um conjunto de enunciações que sustenta a ideia de que o sistema social alternativo dos negros teria sido a primeira tentativa de estabelecer o Estado-Nação no Brasil e de forjar uma nacionalidade brasileira. Eu vou tratar desse assunto com mais profundidade no capítulo IV.

Por hora, vale ressaltar que Beatriz Nascimento (1982d) entende que:

O Quilombo de Palmares, no século XVII, estabelece o primeiro conceito real de Nação, a primeira experiência real de Estado Nacional no Brasil, porque é um estado autônomo, com um sistema fechado, todos os quilombos dos maiores aos menores, dos mais duradouros aos menos duradouros, dos mais antigos aos mais novos, eles estão sempre ligados à noção do estabelecimento político, fundamentalmente político ( p. 11).

Lélia Gonzalez (1982), por sua vez, diz que:

Também não é ressaltado pela história oficial o fato de que o primeiro Estado livre de todo o continente americano existiu no Brasil colonial, como denúncia viva do sistema implantado pelos europeus no continente. Estamos falando da República Negra de Palmares que, durante um século (1595-1695), floresceu na antiga Capitania de Pernambuco (p. 91).

Abdias do Nascimento (1982a) completa que:

O exemplo mais formidável dessa realidade histórica é o da República de Palmares, um estado africano que resistiu de 1596 a 1696: um século inteiro de luta armada contra as campanhas portuguesas, holandesas e brasileiras de extermínio. [...] Esses africanos, fora da existência convencional da sociedade colonial, praticaram a verdadeira abolição da escravatura, junto com seus irmãos e irmãs que se uniram em todas as maneiras concebíveis de resistência, revolta e luta (p. 26-27).

Sabemos que a Negritude foi um movimento iniciado por estudantes da América Latina e da África cujo encontro ocorreu na Europa em plena década de 1930. Eu demonstrei em trabalho anterior (VINHAS, 2010) que a negritude teve versões diversificadas em cada continente e país. No Brasil, outras expressões tiveram a função de embasar movimentos 
similares que buscaram referência nos trabalhos de Luiz Gama, Lino Guedes, Solano Trindade.

A expressão "negritude" seria a versão moderna de outros termos usados no passado.

Vejamos como esses termos aparecem nas enunciações da tríade intelectual:

Existia realmente um "negro" dentro de mim maior, estupendamente maior do que o de fora, mas ele permanecia me negando o direito de ingressar na "democracia racial brasileira". [...] Me sentia na rua um pouco eufórica, por poder pensar calmamente no "meu negro", amá-lo, exibi-lo aos transeuntes, sem medo. Fora de mim existia um negro maltratado, que passa fome, que vive na pior das condições de sobrevivência. [...] Exibi meu "negro" alguns quarteirões abaixo do consultório médico, passeei com ele, subi as escadas de um edifício, onde morava uma amiga a quem ia visitar (NASCIMENTO, 1982b, p. 06-07).

Gonzalez (1988b), por sua vez, diria que:

Quanto a nós, negros, como podemos atingir a consciência efetiva de nós mesmos, enquanto descendentes de africanos, se permanecemos prisioneiros, "cativos de uma linguagem racista"? [...] As implicações políticas e culturais da categoria de Amefricanidade ("Amefricanity") são, de fato, democráticas; exatamente porque o próprio termo nos permite ultrapassar as limitações de caráter territorial, linguístico e ideológico, abrindo novas perspectivas para um entendimento mais profundo dessa parte do mundo onde ela se manifesta: A AMÉRICA e como um todo (Sul, Central, Norte e Insular). Para além do seu caráter puramente geográfico, a categoria de Amefricanidade incorpora todo um processo histórico de intensa dinâmica cultural (adaptação, resistência, reinterpretação e criação de novas formas) que é afrocentrada, isto é, referenciada em modelos como: a Jamaica e o akan, seu modelo dominante; o Brasil e seus modelos yorubá, banto e ewe-fon. Em consequência, ela nos encaminha no sentido da construção de toda uma identidade étnica. Desnecessário dizer que a categoria de Amefricanidade está intimamente relacionada àquelas de Panafricanismo, "Négritude", "Afrocentricity" etc. (p. 76-77).

Abdias do Nascimento (1980) defendia que:

Se nós, descendentes africanos espalhados nos países da diáspora, estamos para forjar uma unidade significativa no sentido de elevar a qualidade de vida da população negra, de melhorar a nossa situação coletiva (pois ela é irredutivelmente coletiva) e compreendemos uns aos outros em nossa situação única, específica, devemos conter resolutamente esse tipo de distorção, produzindo a própria versão da realidade por meio do testemunho escrito (p. 300).

Trago, como último aspecto dessa sequência lógica, o fato de a tríade compartilhar uma análise comum acerca da condição da mulher negra no Brasil. ${ }^{23}$ Em paralelo aos estudos do quilombo, há o ineditismo de Beatriz Nascimento (1976a, 1982, 1990) sobre a participação da mulher negra na dinâmica e na edificação dos quilombos. A tríade intelectual compartilha a pressuposição crítica de que: 1) a gênese da exploração da mulher negra está na sociedade

\footnotetext{
${ }^{23}$ Vale ressaltar que os três incluíam nas análises sobre a mulher negra a sua participação no mercado de trabalho e a relação histórica da sua condição social hedionda no Brasil colonial.
} 
escravocrata; 2) o lugar da mulher negra na sociedade tem relação com uma tríplice discriminação - racial, gênero e de classe; 3) a naturalização da violência contra a mulher negra tem origem na representação da mucama no sistema colonial, perpetuada na imagem da mulata no sistema capitalista.

Vamos deixar ecoar algumas destas enunciações:

A mulher negra, elemento no qual se cristaliza mais a estrutura de dominação, como negra e como mulher, se vê, deste modo, ocupando os espaços e o papeis que lhe eram atribuídos desde a escravidão. A herança escravocrata sofre uma continuidade no que diz respeito à mulher negra. Seu papel como trabalhadora não muda muito (NASCIMENTO, 1976a, p.01).

A perspectiva defendida por Lélia Gonzalez (1982) dizia que:

Ora, na medida em que existe uma divisão racial e sexual de trabalho, não é difícil concluir sobre o processo de tríplice discriminação sofrido pela mulher negra (enquanto raça, classe e sexo), assim como sobre seu lugar na força de trabalho (p. 96).

Abdias do Nascimento (1980) denunciava que:

O abuso sexual à mulher africana e à mulher negra brasileira é mais do que simples abuso: é genocídio, fácil de constatar no crescimento da população mulata e no desaparecimento da raça negra. [...] $\mathrm{O}$ crime de estupro contra a mulher negraafricana pelo branco ocorreu através de gerações. Até os filhos mulatos, herdeiros de um precário prestígio de seus pais brancos, continuaram a prática dessa violência contra a negra (p. 309).

Não creio ser necessário demonstrar exaustivamente como a intelectualidade negra consiste num feixe de relações que torna possível falar de uma unidade discursiva: objetos, modalidades enunciativas, conceitos e estratégias. Dessa forma, é minha intenção neste tópico foi mostrar os níveis em que as enunciações estão ligadas: 1) objetos - quilombo, racismo, mulher negra; 2) modalidades enunciativas compartilhadas - o caráter singular da organização de negros no período colonial ou a ideia de sistema alternativo frente ao modelo colonial; 3 ) conceitos, como o conceito de quilombo, que nem sempre se apresentam numa regularidade, e sim, por vezes, dispersos: a) qualquer unidade organizada por negros, como aparece em Abdias do Nascimento (1982) e Lélia Gonzalez (1982); b) cada sistema social corresponderia a um tipo de organização, como defende Beatriz Nascimento (1981). Eu procuro demonstrar como o campo intelectual brasileiro refrata as relações sociais do espaço social circundante que, por sua vez, reforça o sistema de distinção, hierarquizando entre aqueles que participam do campo 
intelectual brasileiro. Portanto, trata-se de discutir de que maneira um conjunto de princípios impacta sobre o percurso de autores e autoras negros.

\section{CONSIDERAÇões Finais:}

Nesse artigo eu defendi que o dilema da intelectualidade negra no Brasil reside na herança racista do campo intelectual brasileiro. Para tanto, argumentei que este microcosmo social produz um jogo hostil à produção da intelectualidade negra por discordar dos temas, das abordagens e das reflexões, e, principalmente, pelo incômodo provocado pelas contradições apontadas acerca das interpretações de cânones do pensamento social brasileiro sobre a história do Brasil e do negro. É nesse sentido que proponho refletir a relação entre o duplo vínculo ordem científica e ordem social - tal qual aparece no artigo "Ideias fora do lugar e o lugar do negro nas ciências sociais brasileiras", de Ângela Figueiredo e Osmundo Pinho (2002).

Partindo de Thales de Azevedo (1996), pode-se afirmar que no Brasil persiste uma estrutura social baseada no status como forma de ascensão social. A sociedade brasileira não teria sido capaz de concluir a transição de uma sociedade de status, característica do período colonial e da República Velha, para uma moderna sociedade de classes sociais. Para os não brancos, o status de nascimento e a cor da pele seriam fatores de limitação da ordem social independente dos demais elementos condicionantes (AZEVEDO, 1996). Os estigmas corporais tenderiam a reforçar as possibilidades de recusa profissional para as carreiras mais promissoras: nos brancos, a cegueira, a surdez, a gagueira (MICELI, 2001); nos não brancos, a cor da pele, os traços fenotípicos (AZEVEDO, 1996). Para que houvesse uma mudança, seria preciso confrontar as velhas estruturas da organização social com base nas relações de servidão e de apadrinhamento, o que incluiria a formação de quadros de intelectuais (AZEVEDO, 1996). O apadrinhamento era uma forma de mobilidade social individual em oposição à ascensão coletiva da população negra brasileira. (ALBUQUERQUE, 2006).

Insisto que a ausência da intelectualidade negra no campo intelectual brasileiro nem pode ser atribuída exclusivamente à falta de capital simbólico convertido a partir de algum tipo de capital específico, nem por um sistema de disposições particulares - habitus. A noção de habitus foi definida por Bourdieu (2005) como sendo um conhecimento adquirido e também um haver, um capital, indicando a disposição incorporada, quase postural. Isso porque dificilmente a intelectualidade negra corresponde aos critérios estabelecidos pelo campo 
intelectual brasileiro. Mesmo tendo acumulado diferentes tipos de capital específico - cultural, escolar, político, científico - seria particularmente difícil identificar homens e mulheres negros que chegaram efetivamente a convertê-los em capital simbólico: "O capital simbólico é uma propriedade qualquer (de qualquer tipo de capital: físico, econômico, cultural, social), percebida pelos agentes sociais cujas categorias de percepção são tais que eles podem entendê-las (percebê-las) e reconhecê-las, atribuindo-lhes valor" (BOURDIEU, 2011, p. 107).

Tudo leva a crer que, no Brasil, o que determina a posição no campo intelectual vai além da incorporação de um tipo de capital específico - classe, escolaridade, origem transferido para o campo intelectual de um espaço social circundante. Alex Ratts (2006) acredita que a invisibilidade da intelectualidade negra consiste na reprodução de mecanismos de outros microcosmos sociais. Dessa forma, as regras desse microcosmo social implicam a incorporação de elementos determinantes de uma organização social cujas hierarquias rígidas refratam a herança racista - e sexista - da sociedade brasileira. Refiro-me ao que Louis Dumont (1997) descreveu como sendo a base de organização de toda sociedade: a hierarquia como um princípio de gradação dos elementos de um conjunto em relação ao mesmo conjunto. As formas de oposição distintivas e valorativas não apenas vinculam o indivíduo a um sistema de distinção, mas também de hierarquização. É o que se pode chamar de relação hierárquica na qual um elemento simultaneamente participa e se distingue da totalidade de que faz parte, ou seja, ao tempo em que o elemento considerado superior inclui aquilo que é considerado inferior também o exclui (DUMONT, 1997). Portanto, pode-se inferir que, uma vez que a estrutura do campo intelectual brasileiro seria determinada pela relação entre a ordem científica e ordem social, acaba por estabelecer um tipo de vínculo não apenas distintivo, mas também hierárquico. Eduardo de Oliveira e Oliveira, citado por Alex Ratts (2006), defende que vivemos numa sociedade em que a cor da pele e a classe social são primordiais para entender a posição do intelectual negro e negra no campo intelectual brasileiro.

A submissão do campo intelectual brasileiro não apenas colabora no silenciamento da intelectualidade negra, como também aprofunda a discriminação em relação à população negra. Isso ocorre, porque a herança racista desse microcosmo social impõe um jogo que consiste na falta de reconhecimento da diversidade e da pluralidade epistemológica. Esse fato contribui para a contínua invisibilidade das práticas sociais de conhecimento que estão em desacordo com os critérios de produção intelectual estabelecidos pelos que detém o poder no campo. 


\section{REFERÊNCIAS BIBLIOGRÁFICAS:}

AZERÊDO, Sandra. Teorizando sobre gênero e relações raciais. Revista Estudos Feministas, outubro de 1994.

AZEVEDO, Thales de. As elites de cor numa cidade brasileira: um estudo de ascensão social; \& Classes sociais e grupos de prestígio. 2. ed.. Salvador, BA: EDUFBA, 1996.

BHABHA, Homi. O local da Cultura. Belo Horizonte: Editora UFMG, 1998.

BOURDIEU, Pierre. Campo de poder, campo intelectual. Buenos Aires: Folios, 1983b.

BOURDIEU, Pierre. O poder simbólico. Tradução Fernando Tomaz, $8 \circ$ ed. Rio de Janeiro: Bertrand Brasil, 2005.

BOURDIEU, Pierre. Razões práticas: sobre a teoria da ação. 11. ed. Campinas, SP: Papirus, 2011.

COLE, Stephen; COLE, Joanthan R. Scientific output and recognition: a study in the operation of the reward system in science. American Sociological Review, 32 (3), pp. 377-390.

DELEUZE, Gilles. Foucault. Lisboa, PT: Vega, 1987.

DUMONT, Louis. Homo Hierarchicus: o sistema das castas e suas implicações. 2. ed. São Paulo: EDUSP, 1997.

FIGUEIREDO, Ângela; GROSFOGUEL, Ramón. Por que não Guerreiro Ramos? Novos desafios a serem enfrentados pelas universidades públicas brasileiras. Cienc. Cult., São Paulo, v. 59, n. 2, June 2007 . Available from $<$ http://cienciaecultura.bvs.br/scielo.php?script=sci_arttext\&pid=S0009$67252007000200016 \& \operatorname{lng}=$ en\&nrm=iso $>$. access on 03 Oct. 2014.

FOUCAULT, Michel. A arqueologia do saber. Tradução Luiz Felipe Baeta Neves. 3 ed. Rio de Janeiro: Forense, 1987.

GOMES, Nilma Lino. Intelectuais negros e produção do conhecimento: algumas reflexões sobre a realidade brasileira. In: SANTOS, Boaventura S.;MENESES, Maria P. (Orgs.). Epistemologias do Sul. São Paulo: Cortez, 2010 pp. 419-441.

GONZALEZ, Lélia. A Mulher Negra na Sociedade Brasileira: uma abordagem políticoeconômico. In: MADEL, Luz. (org.). O lugar da Mulher: Estudos sobre a condição feminina na sociedade atual. Rio de Janeiro: Graal, V.1, 1982, (Coleção Tendências).

GONZALEZ, Lélia; HASENBALG, Carlos Alfredo. Lugar de negro. Rio de Janeiro: Marco Zero, 1982a.

GONZALEZ, Lélia. Nanny: pilar da Amefricanidade. Revista Humanidades. Brasília: UnB, nº 17, 1988a. 
GRAMSCI, Antonio. Os intelectuais e a organização da cultura. Tradução Carlos Neslson Coutinho. $4^{\text {a }}$. ed. Rio de Janeiro: Editora Civilização Brasileira, 1982.

HALL, Stuart. Da Diáspora: identidades e mediações culturais. Org.Liv Sovik. Trad. Adelaine La Guardia Resente, Ana Carolina Escosteguy e at. all. Belo Horizonte: Editora da UFMG, 2003.

HOOKS, Bell. Intelectuais negras. Estudos Feministas, Ano 3, Tradução: Marcos Santarrita, ISSN 0104-026X, Florianópolis, 1995, pp. 464-478.

LATOUR, Bruno. Reassembling the social: an introduction to actor-network-theory. New York: Oxford University Press, 2005.

MENESES, Maria Paula Gutierrez. A questão da universidade pública em Moçambique e o Desafio da Pluralidade de Saberes. In: Cruz e Silva, Teresa e Outros. 'Lusofonia' em África. História, Democracia e Integração Africana. Dakar: CODESRIA, 2005, pp.45-66.

NASCIMENTO, Abdias do. O quilombismo: documentos de uma militância pan-africanista. Petrópolis, RJ: Vozes, 1980.

NASCIMENTO, Abdias do. O Negro Revoltado, Rio de Janeiro: Nova Fronteira, 2a . Ed., 1982a.

NASCIMENTO, Beatriz. Por uma história do homem negro. Revista de Cultura Vozes. 68(1), 1974a, pp. 41-45.

NASCIMENTO, Beatriz. A mulher negra no mercado de trabalho. Jornal Última Hora, Rio de Janeiro, 25 de julho, 1976a.

NASCIMENTO, Beatriz. O Quilombo do Jabaquara. Revista de Cultura Vozes 3, 1979, pp. 176-178.

NASCIMENTO, Beatriz. Kilombo e memória comunitária: um estudo de caso. Rio de janeiro, Estudos Afro-Asiáticos 6-7, 1982c, pp. 259-265.

NASCIMENTO, Beatriz. O conceito de quilombo e a resistência cultural negra. Afrodiáspora Nos. 6-7, 1985, pp. 41-49.

QUIJANO, Aníbal. Colonialidade do poder e classificação social. In: SANTOS, Boaventura S.;MENESES, Maria P. (Orgs.). Epistemologias do Sul. São Paulo: Cortez, 2010 pp. 73-118.

RATTS, Alecsandro (Alex) J. P. Eu sou atlântica: sobre a trajetória de vida de Beatriz Nascimento. São Paulo: Instituto Kuanza; Imprensa Oficial do Estado de São Paulo, 2006.

SAID, Edward W. Representações do intelectual: as Conferências Reith de 1993. São Paulo, SP: Companhia das Letras, 2005. 
SIRINELLI, Jean-François. As elites culturais. In: RIOUX, Jean-Pierre; SIRINELLI, JeanFrançois. Para uma história cultural. Lisboa: Estampa, 1998.

SOUZA, Florentina. Autorrepresentação e intervenção cultural em textualidades afrobrasileiras. Revista da ABPN, América do Norte, 1, jul. 2010. Disponível em: HTTP://WWW.ABPN.ORG.BR/REVISTA/INDEX.PHP/EDICOES/ARTICLE/VIEW/88. Acesso em: 08 Fev. 2013.

SPIVAK, Gayatri Chakravorty. Pode o Subalterno Falar? Belo Horizonte: Editora UFMG, 2010.

VINHAS, Wagner. Narrativas em Negociação: o caso da invenção das tradições em Salvador, 2010. (Dissertação de Mestrado em Ciências Sociais) - Universidade Federal da Bahia, UFBA, Salvador.

WEST, Cornel. The dilema of the Black Intellectual. The Journal of Backs in Highter Education. Winter, 1993/1994, p. 59-67. Disponível em: http://academiccommons.columbia.edu/ download/fedora_content/download/ac:157329/CONTENT/The_Dilemma_of_the_Black_Int ellectual.pdf 